\title{
História Oral, questões sensíveis e a historiografia oral brasileira
}

\section{Eloisa Rosalen*}

ORCID iD https://orcid.org/0000-0001-5125-9969

Universidade Federal de Santa Catarina, Programa de Pós-Graduação em História, Florianópolis, Brasil

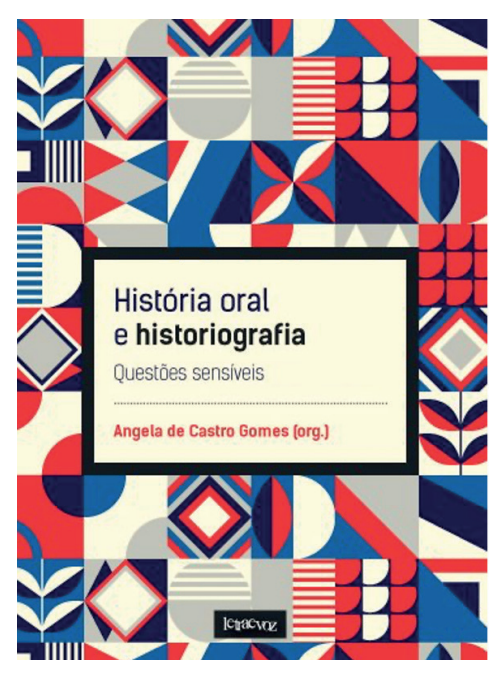

GOMES, Angela de Castro (Org.). História oral e historiografia: Questões sensíveis. São Paulo: Letra e Voz, 2020.

Doutoranda em História na Universidade Federal de Santa Catarina (UFSC), com orientação da Profa. Dra. Joana Maria Pedro. E-mail: rosaleneloisa@gmail.com. 
Em continuidade à coleção História Oral e dimensōes do público, ${ }^{1}$ foi lançada, no ano de 2020, a obra História oral e historiografia: Questóes sensiveis, organizado por Angela de Castro Gomes. O livro constitui um misto de experiências de pesquisas, análises de narrativas orais sobre diversas temáticas, levantamentos de produçóes historiográficas das últimas quatro décadas e debates pertinentes sobre as questôes sensíveis que envolvem a utilizaçáo das fontes orais. $\mathrm{O}$ objetivo, como apontado na introdução, foi "fazer um mapeamento [...] do impacto que o uso da metodologia da História Oral produziu no campo das pesquisas acadêmicas de História, no Brasil, em especial a partir dos anos de 1980" (Gomes, 2020, p. 7).

Angela de Castro Gomes tem reconhecimento no campo da historiografia oral, sendo uma das propulsoras do campo no Brasil. Iniciou, como lembra no último capítulo do livro, a utilizar a História Oral a partir da segunda metade dos anos de 1970. A autora também foi coordenadora de diversos projetos que tinham como objeto a história política do Brasil República, a história de intelectuais, a cidadania e os direitos do trabalho, a historiografia, a memória e o ensino de história. Além disso, dirigiu o Centro de Pesquisa e Documentação de História Contemporânea do Brasil (CPDOC) dos anos de 1988 até 1994, onde, hoje, é professora emérita; centro este conhecido pelos acervos e pesquisas que se utilizaram da História Oral.

O livro História oral e historiografia é divido em oito capítulos, nos quais são contempladas as interconexóes com diferentes temáticas e sujeitos, tais como: o papel do testemunho, o movimento estudantil, o movimento negro e o racismo no Brasil, os trabalhadores e trabalhadoras, a imigração por meio do refúgio político, as doenças, as relaçôes de gênero e a perspectiva dos/as historiadores. A chave de leitura de todos os capítulos são tanto as produçôes historiografias que envolvem questôes sensíveis quanto a maneira como estes mesmos aspectos atravessaram as suas pesquisas. Em outras palavras, todas as pesquisadoras e pesquisadores oferecem ao longo de seus capítulos uma leitura que interconecta historiografia oral e as questóes sensíveis que permeiam as temáticas estudadas.

No primeiro capítulo, intitulado História Oral e memória da ditadura militar: o papel do testemunho, Maria Paula Nascimento Araújo apresentou sua interconexáo a partir dos dois caminhos: o levantamento com as produçóes acadêmicas sobre a ditadura que se utilizaram da metodologia da História Oral e a reflexão sobre as políticas de memórias implementadas pelo Estado. O papel do testemunho, seja ele jurídico, psíquico, ou historiográfico, se tornou a palavra-chave. Da mesma forma que o trauma e a tortura encontrados nos acervos sensíveis também sinalizam um importante aspecto para quem trabalha com a história oral da ditadura brasileira. A autora ainda sinalizou que trabalhar com tais acervos é um desafio para o historiador, porque, além

1 Trata-se da coleção de mais de dez livros lançada pela editora Letra e Voz, que contemplam as diversas temáticas, como estudos de gênero, migrações, mídia, patrimônio cultural, arte, movimentos sociais. 
da complexidade das questôes teóricas e metodológicas, "demandam um compromisso profundo com a democracia e, sobretudo, com uma prática orientada pela empatia e pela valorização dos Direitos Humanos" (Gomes, 2020, p. 32).

A temática da ditadura perdura também no segundo capítulo, onde Angélica Muller apresenta o movimento estudantil por meio do texto denominando História Oral e movimento estudantil: entre demanda social e produção historiográfica. A autora buscou demostrar a transformação dos estudos sobre o movimento estudantil na atualidade e a contribuiçáo que a História Oral teve nesta mudança. Para isso, e além do levantamento das produçóes historiográficas dos últimos anos, o capítulo deu destaque à pesquisa realizada por meio do "Projeto Memória do Movimento Estudantil" e à criação de novas fontes orais por meio das Comissóes da Verdade que ocorreram em diversas universidades brasileiras. Pareceu-me que o pressuposto do texto está baseado no fato de que o movimento estudantil na ditadura é por si só um tema sensível. No entanto, longe de querer questionar este aspecto, senti falta da maneira como as questôes sensíveis atravessaram a pesquisa e estão participando do processo de produção da história do movimento estudantil.

A partir do terceiro capítulo, as múltiplas identidades ${ }^{2}$ tomam maior espaço no livro. Não que não estivessem atravessadas nos capítulos anteriores. Mas, foi nos capítulos seguintes que foram mobilizaras pelas autoras e autores. Com o capítulo intitulado História Oral, movimento negro e racismo no Brasil, Amilcar Araujo Pereira e Thayara C. Silva de Lima explicitam as experiências de racismo vividas por pessoas do movimento negro no âmbito escolar. A leitura oferecida pelo autor e a autora foi de que "o racismo é um tema sensível" e foi "nas últimas décadas [que este tema] vem sendo pesquisado como nunca antes em nosso país" (Gomes, 2020, p. 59). O capítulo trouxe inúmeros aspectos, como as práticas e os silenciamentos, a desumanização com o racismo, a compreensáo sobre as violências sofridas e a identidade negra, as reflexóes acerca de uma educação antirracista e a relação com o movimento negro. Tem destaque as narrativas escolhidas que são carregadas de sentimentos.

No quarto capítulo, intitulado História Oral e história social do trabalho: os migrantes nordestinos em São Paulo entre os anos 1940 e 1960, escrito por Paulo Fontes, foram analisadas tanto a relação entre História Social do Trabalho e História Oral quanto as narrativas dos trabalhadores da Cia. Nitro Quimica Brasileira e dos moradores do bairro São Miguel Paulista, Zona Leste de São Paulo. A partir das análises, quatro grandes temas emergiram: 1) a experiência da migração, 2) os desafios e as dificuldades da vida cotidiana num bairro periférico de São Paulo, 3) as experiências de trabalho e 4) a invenção de uma identidade nordestina (Gomes, 2020, p. 89). É interessante destacar

As identidades podem ser entendidas, de maneira geral, como a maneira que um indivíduo se entende em relação a algo ou alguma coisa. Nela estão envolvidas questões como construção de si, identidades individuais/coletivas e identidade social, identidades e memórias, identidade cultural, aspectos contextuais, entre outras. Para saber mais, ver: Hall (2015). 
que embora o foco da pesquisa não esteja ligado aos estudos de gênero, o autor sinaliza a existência de hierarquias atreladas aos trabalhos desempenhado pelas mulheres. As questôes sensíveis aparecem menos explícitas.

Os refugiados políticos no Brasil são os sujeitos do capítulo de Méri Frotscher e Marcos Nestor Stein, cujo título é História Oral e questôes sensiveis em pesquisas sobres refugiados no Brasil. Como nos demais capítulos, a autora e o autor tanto mapearam as produçôes acadêmicas no âmbito da pós-graduação das últimas décadas, que tiveram como sujeitos os refugiados, quanto trouxeram as questôes sensíveis que aparecem nestas pesquisas e na pesquisa de autoria; sobretudo, destacaram os "traumas, ressentimentos, disputas em torno da memória da guerra e da construção de uma nova pátria no Brasil" (Gomes, 2020, p. 108). As questóes sensíveis elucidadas são muitas, como a autoidentificação ou não como refugiados, os debates em torno do anonimato, os silêncios, as narrativas das vítimas e os sofrimentos. Por último, o capítulo apresentou a importante reflexão de que "talvez o grande desafio para o pesquisador seja aliar o cuidado com o entrevistado e o rigor acadêmico, ao realizar a análise crítica das narrativas que verbalizam os sofrimentos, os traumas e os ressentimentos vividos" (Gomes, 2020, p. 125).

No capítulo de Dilene Raimundo do Nascimento e Eliza da Silva Vianna, intitulado História Oral, sensibilidades e história das doenças, o tema sensível é o impacto da doença por meio da experiência da aids. O objetivo do capítulo foi apresentar (ademais do breve panorama das contribuiçôes da História Oral para o campo de estudos da história das doenças) "as sensibilidades que emergiram em entrevistas realizadas durante uma pesquisa sobre a história da aids no Brasil” (Gomes, 2020, p. 130). Em outras palavras, o capítulo entrelaça as questóes sensíveis com as narrativas de duas entrevistadas e suas existências em relaçáo à doença. Também foi dado destaque sobre como o gênero imprime aspectos fundamentais no que tange às experiências do cuidado, da compreensão de si e das questóes sensíveis. O capítulo transpira emoção do início ao final ao trazer as narrativas sobre aspectos relacionados tanto ao cuidado de uma pessoa doente quanto à descoberta e à vivência da enfermidade.

Os estudos de gênero, as questóes sensíveis e a historiografia ficaram a cargo de Lídia Possas, no capítulo História Oral, tempo presente e estudos de gênero. Nele, a autora abordou as "contribuiçóes da História Oral no campo dos estudos de gênero no tempo presente" por meio de pesquisa sobre a fuga de mulheres do Cárcere Buon Pastor em Córdoba, na Argentina. As questóes sensíveis de gênero mobilizadas foram: o silenciamento das vozes das mulheres, a maternidade, a hierarquia entre as mulheres presas, a condição como "mulher de desaparecido", entre outras. A autora reflete, a partir das hierarquias de gênero e a historiografia, que a História Oral "nos possibilita retomar as subjetividades, as narrativas repletas de emoção e, principalmente, dos sujeitos femininos silenciados pela tradição de uma história oficial" (Gomes, 2020, p. 179). 
Todos os capítulos até aqui abordaram as questōes sensíveis e historiográficas a partir de suas temáticas de pesquisa e do ponto de vista dos sujeitos entrevistados. Angela de Castro Gomes, como anunciou no título História Oral, historiadores e questöes sensiveis: um giro no parafuso, inverte o eixo ao abordar o experimento da sensibilidade a partir da perspectiva da entrevistadora. Como nos lembra a autora "o entrevistador[a] é, muitas vezes, o primeiro entrevistado[a] deste processo" (Gomes, 2020, p. 188). Ao "compartilhar momentos" que considerou "de grande aprendizado", como historiadora oral do mundo do trabalho, a autora lembrou - de maneira indireta - sobre o diálogo e as trocas de conhecimento no processo de elaboração das fontes orais (Portelli, 2010). Em outras palavras, sinalizou tanto sobre o processo de aprendizagem adquirido por meio de entrevistas quanto como a subjetividade em relaçáo às trocas com seus entrevistados foi moldando a sua prática como historiadora oral. A obra não poderia encerrar melhor.

O livro tem muitos méritos e contribuiçôes para o pensamento crítico, analítico e historiográfico da História Oral. O ponto de bastante destaque foi focálo nas produçôes e experiências de pesquisas brasileiras que envolveram o campo de conhecimento e, também, nos levantamentos de publicaçôes, teses e dissertaçóes. Esta característica faz deste material único e importante, a fim de entender como a História Oral cresceu e se desenvolveu no Brasil nas últimas décadas. A constituição do campo da História Oral brasileira se deu, como anunciado na introdução do livro, por meio da expansão de pesquisas acadêmicas a partir da década de 1980. Foi também nas últimas duas décadas que se deu o crescimento de financiamentos que possibilitaram as produçóes historiográficas citadas nos capítulos. O contexto brasileiro, como sinalizado, também trouxe inúmeras transformaçôes por meio das Comissóes da Verdade, da Lei $\mathrm{n}^{\circ} 10.639 / 03^{3}$ (que tornou obrigatório o ensino da história e cultura afro-brasileira), e da maior visibilidade dos estudos de gênero.

O livro História oral e historiografia: Questôes sensiveis, organizado por Angela de Castro Gomes, é uma importante leitura sobre as pesquisas da História Oral e, também, para quem busca entender como as questôes sensíveis permeiam as diversas temáticas que se utilizam da História Oral no Brasil. Se torna leitura obrigatória para todas/os historiadoras/es orais. Minha crítica reside naquilo que buscava ao iniciar a leitura: quais são os limites impostos pelas questóes éticas em relação aos aspectos sensíveis? Ou melhor, como mobilizar ou se utilizar das questóes sensíveis sem perder no horizonte a crítica e a ética historiográfica? Em outras palavras, como lidar com os traumas, emoçôes e sensibilidades sem ferir ou perturbar (por meio das nossas entrevistas, análises ou rigor acadêmico) as angustias de cada sujeito? De maneira bastante próxima estas questôes foram lançadas no capítulo de Méri Frotscher e de Marcos Nestor Stein (anunciada nesta resenha), mas ficaram sem respostas no livro.

Disponível em: http://www.planalto.gov.br/ccivil_03/leis/2003/110.639.htm. Acesso em: 15 jun. 2021. 


\section{Referências}

HALL, Stuart. A identidade cultural na pós-modernidade. 12. ed. Rio de Janeiro: Lamparina, 2015.

PORTELLI, Alessandro. Sempre existe uma barreira: a arte multivocal da história oral. In: PORTELLI, Alessandro. Ensaios de história oral. São Paulo: Letra e Voz, 2010. p. 19-35.

Recebido em 28/09/2020.

Versão final reapresentada em 01/02/2021.

Aprovado em 01/03/2021.

Fonte de financiamento: Conselho Nacional de Desenvolvimento Científico e Tecnológico (Capes) - Bolsa.

Conflitos de interesse: nada a declarar. 